Valencia-Arias, J. A. (mayo - agosto, 2019). ¿Por qué es importante para un investigador ser visible en las redes sociales académicas? Revista Virtual Universidad Católica del Norte, (57), 1-2. doi: https://doi.org/10.35575/rvucn.n57a1

\title{
Editorial
}

\section{¿Por qué es importante para un investigador ser visible en las redes sociales académicas?}

\author{
Jhoany Alejandro Valencia-Arias \\ Doctor en Ingeniería, Industria y Organizaciones \\ Instituto Tecnológico Metropolitano \\ jhoanyvalencia@itm.edu.co \\ Orcid: https://orcid.org/0000-0001-9434-6923
}

Para los investigadores la identidad digital se convierte en su marca personal en los múltiples servicios que conforman la web 2.0; esto se debe a que internet se ha convertido en una herramienta para la difusión y el acceso de la información, por lo que además conlleva una gran responsabilidad sobre la validez de la información que se comparte. Esta identidad es una representación, en términos de reputación, relevancia y visibilidad, dado a la difusión del trabajo como evidencia, en aras de establecer indicadores ligados a referencias regionales, nacionales o internacionales.

Desde esta perspectiva, la marca que desarrolla el investigador es dinámica, resultado de las interacciones entre la proyección y la percepción de este con la comunidad, permitiendo que se forme una red social de intercambio de conocimientos y recursos, propia de la Web 2.0. La utilidad de un perfil en las redes sociales académicas se concentra en la difusión de la actividad investigativa, la posibilidad de realimentarse de otras investigaciones y de otros investigadores, fomentar el trabajo cooperativo, incrementar la visibilidad, incentivar el posicionamiento personal en el campo de conocimiento y favorecer la formación de alianzas estratégicas.

Adicionalmente, es uno de los factores más influyentes en la visibilidad y capacidad de recibir citas, lo cual se logra manteniéndose activo en la red y creando perfiles públicos en las principales bases de datos científicas. Algunas estrategias para mejorar la visibilidad están asociadas con la simplicidad en la búsqueda de la identidad del investigador, y la necesidad de tener un nombre de marca único que sea consistente y fácil de identificar. Para García-Peñalvo (2018) la elección del nombre ayuda a la diferenciación con otros autores, con coincidencias parciales, pues la falta de uniformidad del mismo afecta las métricas científicas, teniendo una influencia directa en el seguimiento a las citas.

Por otro lado, se debe hacer una búsqueda en comunidades y redes sociales académicas donde el tema de interés del investigador tenga mayor actividad, así como generar contenido de calidad para el público objetivo: miembros de comunidades científicas e investigativas, ampliando su contenido, llegando cada vez a más personas, forjando su reputación y, como consecuencia, teniendo una mayor visibilidad. La red, además, ofrece varios recursos para hacer esta divulgación, entre ellos las plataformas de acceso libre, tales como blogs, portales académicos o sitios web especializados, donde textos, imágenes y videos son los insumos fundamentales para esta gestión en redes sociales. 


\section{EDITORIAL}

\section{Presentación | Revista virtual}

Universidad Católica del Norte, 57, 1-2

ISSN: 0124-5821 (En línea).

En este sentido, una estrategia general de comunicación se puede centrar en: la búsqueda inicial de repositorios y sitios gratuitos para almacenar las publicaciones (como son los repositorios), y en la necesidad de construir identidad académica digital, con perfiles académicos en diferentes herramientas, como son: bases de datos, repositorios institucionales, motores de búsqueda académicos, entre otros.

Finalmente, para ejemplificar el impacto que tiene la difusión del conocimiento, Lawrence (2001) encuentra que, mediante la publicación de artículos en internet de forma gratuita, se incrementa en un factor de 2.6 la cantidad de citas que este artículo puede recibir según su media. Esto quiere decir: cada artículo publicado Online puede llegar a una media de 7.03 citaciones, mientras que los publicados Offline (no incluido internet) cuentan con una media de 2.17 citas.

\section{Referencias}

García-Peñalvo, F. J. (2018). Identidad digital como investigadores. La evidencia y la transparencia. Education in the Knowledge Society, 19(2), 7-28.

Lawrence, S. (2001). Free online availability substantially increases a paper's impact. Nature, 411(6837), 521-522. 